\title{
ICT in Energy Security and Efficiency Assurance
}

\author{
Youssef Tabsh ${ }^{1}$, Vida Davidavičiené ${ }^{2}$ \\ ${ }^{1,2}$ Department of Business Technologies and Entrepreneurship, Faculty of Business Management, \\ Vilnius Gediminas Technical University, Vilnius, Lithuania \\ E-mails: ${ }^{1}$ Youssef.tabsh@lau.edu1 (corresponding author), ${ }^{2}$ vida.davidaviciene@vgtu.lt
}

\begin{abstract}
Nowadays the energy consumption is increasing drastically in the world, many factors are determining the need for it. The important factors vary from socioeconomic to the increase of the population. Due to the aforementioned factors, the need for the energy security and efficiency assurance is becoming very essential to secure energy resources in the world in general and in the developing countries specifically. A qualitative research was conducted in this article to find the newest resources determining the need for ICT implementation in energy security and efficiency. This article will identify and evaluate how information and communication technologies contribute to the energy security and efficiency assurance.
\end{abstract}

Keywords: Sustainability, ICT, resources, energy, efficiency, assurance.

\section{Introduction}

In the modern context, the energy crisis has been observed to be one of the major emerging issues due to its rising demand as well as reducing supply. The reason behind the energy crisis is the limited availability of oil resources along with the restricted supply due to the geographical barriers along with political conflicts (McKillop, 2008; Williams \& Alhajji, 2003). The growing concern of energy crisis is also due to its over-consumption, rising population of the world, poor infrastructure for its efficient \& effective management, and unexplored renewable energy options. 
It also includes a delay in commissioning of power plants and excessive wastage of energy by the consumers. It is also due to the poor distribution system, especially in the rural areas, the occurrence of major accidents \& natural calamities, the breakdown of wars, and attacks along with the imposition of higher taxes among others (Armaroli \& Balzani, 2007; Mensah-Bonsu \& Oren, 2002). Additionally, the energy crisis severely affects the economy, as it restricts the operational process of industries, thereby causing unemployment to a certain extent. It further increases the expenditure of daily life of the people, thus affecting the society. It influences to use energy, which causes pollution, thereby affecting the environment (Kilian, 2008; Lee \& Ni, 2002). However, there are arguments that the use of Information and Communications Technology (ICT) supports in energy management. In this context, ICT is the use of all possible technologies for the purpose of telecommunication, development of intelligent management system, broadcasting of media, audiovisual processing, and network-based information processing (Wang \& Woo, 2007; Chapelle, 2003).

The above-mentioned background information motivated in conducting research to identify and assess the way ICT can be used in energy security as well as efficiency. In this regard, the rationale behind conducting this research has been to identify and evaluate the positive effects of implementing ICT for reducing the technical problems, lowering the cost, maintaining energy management security, and assuring efficiency. Further motivation has been gained from the fact that this study attempted to determine and evaluate the ways through which the energy problems in the underprivileged nations can be mitigated.

The causes of energy crisis involve its rising population, overconsumption, poor infrastructure, excessive wastage, unexplored renewable energy options, poor distribution system, and occurrence of wars \& attacks. This also includes natural calamities along with the imposition of higher taxes among others. Energy crisis results in high inflation, industrial slowdown, unemployment, and poverty. Thus, energy security and efficiency assurance are important for the social, economic, and environmental development. In this context, ICT plays a crucial role in communication and information processing. 
Based on the aforementioned background information and rationale for the research, a specific research aim to identify and evaluate how ICT contribute to energy security and efficiency assurance has been depicted. Following research objectives framed for this study:

- To tackle the intervention of ICT in energy management security and efficiency assurance

- To identify and evaluate the positive effects of implementing ICT in reducing the technical problems in energy management security and efficiency assurance

- To find and analyze the positive effects of the implementation of ICT in reducing the cost of energy management security and efficiency assurance

- To identify and evaluate the positive effects of implementing ICT in maintaining efficient and effective energy supply

- To identify and assess the ways through which the energy problems in the third world countries can be addressed

To attain the aim of the research, the qualitative method has been used, wherein secondary data were extensively utilized. These data were then analyzed in a descriptive qualitative way. The implementation of ICT will reduce the technical problems, lowers the cost, and maintain effective energy management security as well as efficiency assurance. This will largely support the third world countries to overcome the issues of the energy crisis.

\section{Literature Review}

One of the major causes of the energy crisis is its increasing demand in the global context. Contextually, the increasing demand has also been due to the rising population throughout the world (Coyle \& Simmons, 2014). The underdeveloped nations such as Pakistan face financial issues with reduced cash flow. Hence, this, in turn, affects the supply of supply of energy (Qasim \& Kotan, 2013). The growing concern for the environment protection from the use of fossil fuel has resulted in the restriction in its consumption (Festus \& Ogoegbunam, 2015). Climate change in the 
global context has also led to the growing concern for environmental protection (Pathak, 2014). In addition, the poor infrastructure has also been the reason for the global energy crisis, which increases the production cost as well as complexity associated with it (Coyle \& Simmons, 2014). Moreover, the wastage of energy has been a common phenomenon in both urban and rural areas, which, in turn, causes its crisis at the time of requirement (Pathak, 2014). In Pakistan, the energy distribution system is poor due to the lack of proper infrastructure. Hence, due to this particular reason, the country faces a crisis in both rural and remote areas (Qasim \& Kotan, 2013). During wars, especially evident from World War II, there have been severe international political conflicts, which resulted in an energy crisis in some nations (Coyle \& Simmons, 2014). Natural calamities also affect the supply chain process, especially in the case of oil pipeline burst due to which energy cannot be distributed to the destination. The heavy taxes on oil and automobiles causes energy crisis to a certain extent (Coyle \& Simmons, 2014).

The phenomenon of energy crisis adversely affects people all round the world (Festus \& Ogoegbunam, 2015). Energy crisis results in higher inflation rate along with the increase in the price of goods and services. It also leads to uncertainty in the economy of the respective nation (Mbunwe, 2014). It results in increased level of unemployment rate within the nation, which is mostly due to the insufficiency of energy for running the industries and plants, which ultimately increases poverty (Festus \& Ogoegbunam, 2015). Energy crisis results to political conflicts, not only in the international context but also at a domestic level. The rising fuel price, inflation, unemployment, and poverty influence the public to revolt against the government (Whitford, 2016). Energy influences people to use sources that cause pollution. Thus, it severely threatens the global climatic change (Manieniyan, Thambidurai, \& Selvakumar, 2009). Energy crisis results into the devaluation of the domestic currency, reduction of foreign reserve, and a rise in lending rate. It affects the infrastructural growth as well as insufficiency of funds cause the government to prepare a low budgetary plan for social development (Festus \& Ogoegbunam, 2015).

Energy security and efficiency assurance is highly important for economic growth as well as development along with its sustainability in the long run. It leads to 
industrial growth, which in, turn, increases employment and the purchasing power of the people. It significantly contributes to reducing the inflation rate as well as poverty among people (Stošić-Mihajlović \& Trajković, 2018). Moreover, energy security and efficiency assurance is crucial for saving the planet, as it reduces pollution and carbon footprint along with the lowering of the possibility of climate change (Volyand, Woodman, Hook, Reece, \& Fagan, 2010). Energy security along with efficiency assurance leads to the welfare of the society, as it promotes industrialization and establishes modern societies. It also ensures the development of a clean and healthy environment for the people (Bokor, 2013). Besides, energy security and efficiency assurance leads to a reduction in the operational costs of the respective companies (Mechtenberg, 2009).

In the present context, ICT plays a crucial role in all aspects, thereby contributing to the betterment of the life of people (Sharma, Gandhar, Sharma, \& Seema, 2011). ICT largely supports in enhancing the knowledge of the people throughout the world regarding various aspects. Thus, people by using this gained knowledge can contribute to own betterment in several fields (Luić \& Glumac, 2009). ICT in the modern day context is mainly used in learning. It involves the presence of various technologies, which can be used for learning. This includes the internet, extranet, intranet, TV audio-videotape, and CD-ROM among others, wherein information are stored. Hence, the individuals can use conveniently this information for self-learning (Sharma, Gandhar, Sharma, \& Seema, 2011). The role of ICT is in improving the interactive learning of people, which is especially through PowerPoint, Excel, Access, animation, and graphics among others. Apart from the improved learning scope from the use of ICT, it also plays a role in enhancing problem-solving and decision-making skills. Thus, ICT can be used for effective problem solving along with decision making of the various issues related to people. This also implies the issue energy crisis can be solved as well as effective decisions can be taken for the energy security and efficiency assurance (Sharma, Gandhar, Sharma, \& Seema, 2011).

The role of ICT in using Emerging Learning Technologies (ELT) such as blogs, podcast, and wikis among others supports in enhancing one's knowledge (Sharma, Gandhar, Sharma, \& Seema, 2011). The role of ICT in improving business practices 
through improved communication and coordination with all the stakeholders. Additionally, it supports in the effective decision making and problem solving of the business by successfully using and analyzing the available information (Luić \& Glumac, 2009). The online buying and selling of goods and the conducting electronic business activities have been feasible through the development of ICT. This helps in enhancing the business efficiency along with reducing cost. Thus, it offers similar scope to the energy producing and dealing companies to lower the cost and enhance efficiency (Luić \& Glumac, 2009). ICT is crucial for enhancing the human resource management (HRM) and customer relationship management (CRM). Hence, this, in turn, leads to the improved satisfaction of employees as well as the customers, thereby benefiting the respective business (Singh, 2016). Moreover, ICT plays the role of conducting e-governance, which, in turn, ensures the effective implementation of the policies. Thus, the government can effectively implement energy security and efficiency assurance policies (Luić \& Glumac, 2009).

\section{Research Methodology}

In order to successfully attain its aim of this research, a qualitative approach has been used. This is owing to the nature of the research, which can be effectively conducted by the qualitative method. The research attempted to identify and analyze the ways through which ICT contributes to energy security and efficiency assurance. Hence, this can be attained through the use of secondary sources and are analyzed in a descriptive way. Besides, the use of a qualitative approach can be justified by stating that it led to the in-depth analysis. From the perspective of a researcher, it also enhanced the understanding of the subject matter. In addition, it further ensured that the research outcome to be aligned with the research aims along with the research objectives (Smith, 2015; Maxwell, 2012; Giorgi, 2009).

In this qualitative research, the data were collected from credible secondary sources. In this context, it mainly included scholarly journal articles and books. The reason behind such consideration is that the scholars, as well as the authors, have extensive knowledge and experience about a specific topic of research. They also have good 
research and analytical skills, thus the findings in these sources are highly reliable in nature. Besides, the scholarly journal articles and books that were published within the past 10 years, i.e. from 2009 to 2018 were considered for the research. This is for ensuring that the research outcome obtained from this study is relevant to the present day context. Thus, the collected secondary data ensured that the research to be reliable, relevant, and valid, which, in turn, assured its success (Quinlan, Babin, Carr, \& Griffin, 2018; Lillis \& Curry, 2013; Gratton \& Jones, 2010).

The collected credible secondary data has been analyzed in a qualitative way. The secondary data were interpreted on a logical basis from the perspective of a researcher. The data were further illustrated in a descriptive way, which aligned with the research aim along with the research objectives. This, in turn, ensured the attainment of the desired outcome. The information collected from one source was verified as well as justified with that of the others. This cross verification of the collected data led to the research triangulation. Thus, the eventual outcome obtained from the research has been highly reliable, relevant, and valid (Silverman, 2016; McDaniel \& Gates, 2013; Ritchie, Lewis, Nicholls, \& Ormston, 2013).

In this study, all the possible ethical values of research have been integrated that are relevant. This has helped in ensuring greater acceptance of the research throughout the world, thereby reflecting its overall success. In this research, there has been no attempt to conduct plagiarism. In addition, it also did not involve the infringement of any copyright protection. The data from varied sources were read and further interpreted in the study in own language. The authors and scholars from whom the secondary data were collected were also acknowledged through proper citation. In addition, the study also focused on avoiding plagiarism. There has been no attempt to interpret the information collected in a biased way (Flick, 2018; Ritchie, Lewis, Nicholls, \& Ormston, 2013; Miller, Birch, Mauthner, \& Jessop, 2012).

\section{Discussion and results}




\subsection{The Positive Effects of the Implementation of ICT in Reducing the Technical Problems in Energy Management Security and Efficiency Assurance}

The implementation of ICT largely impacts and benefits with respect to energy management security and efficiency assurance. It significantly supports in reducing the technical issues in the energy management. In this context, it can be analyzed that ICT supports in improved communication between the stakeholders of energy producing companies. This, in turn, assists in addressing the quality issues. It further supports in conducting research as well as witnessing innovation for increasing the energy density. There has been a serious issue that the voltage of the electric power has been relatively low in many regions of the world. This can be addressed through the implementation of ICT. The energy sector also has the issue of mobility, especially relating to the transfer of oil from one region to the other. The instances of oil pipeline burst due to natural calamity or some criminal groups can threaten its security and efficiency assurance. In this regard, the use of ICT is highly effective in tracking whether there is any burst in the pipeline so that the repair can be done immediately. Through the use of ICT, the customers or any other stakeholder of the sector can inform to the respective authority regarding the occurrence of supply break. It can thus be effectively communicated through telephonic calling along with messages (Gubbi, Buyya, Marusic, \& Palaniswami, 2013; Yan, Qian, Sharif, \& Tipper, 2013; Gharavi \& Ghafurian, 2011).

The use of ICT is also helpful in finding new sources of energy through extensive research and employment of varied related technologies. Thus, it can help in overcoming the global challenges related to the energy crisis. It can also be evaluated that ICT can be effectively utilized for improving the infrastructure for efficient production, management, and distribution of energy all over the world. The energy sector has also been facing the issue of excessive wastage, which, in turn, causes the crisis to a certain extent. In this regard, the use of ICT is extensively effective, as it leads to the identification of the areas, which generates wastage. The use of various 
ICT tools can also be used for addressing the issue (Gubbi, Buyya, Marusic, \& Palaniswami, 2013; Yan, Qian, Sharif \& Tipper, 2013; Gharavi \& Ghafurian, 2011).

\subsection{The Positive Effects of the Implementation of ICT in Reducing the Cost in Energy Management Security and Efficiency Assurance}

The use of ICT in the energy sector has also led to the reduction of the cost of energy management security and efficiency assurance. This has been apparent from the fact that ICT significantly contributes to the energy sector by increasing productivity as well as rationalizing the process. This, in turn, directly contributes to the reduction of the operational cost of the company. However, ICT further ensures that the reduction of cost does not affect the quality of the product or service, customer satisfaction, and revenue collection. Moreover, ICT involves technologies such as internet along with GPRS, which can be effectively used for tracking the performance of the energy supply chain process. The use of this technology is highly cost benefits with respect to energy management and energy efficiency process. ICT also involves the use of technologies such as radio frequency at relatively lower expenditure support in identifying the energy cost, the power use, and the generation of greenhouse gas (Amin, 2015; Clastres, 2011; Moslehi \& Kumar, 2010).

Additionally, another tool of ICT that offers cost benefit to the energy sector is the approach of video conferencing. In energy management security and efficiency assurance, the individuals included do not have to visit physically for resolving any issue or take decisions. They can, in fact, communicate through video conferencing technology, which is less costly as compared to the physical aspects. The use of ICT also supports in reducing the costs of the energy generation process as well as a reduction in carbon emission. Cloud technology is a crucial aspect in ICT, which supports in the decreasing the cost in the automation process for energy use. It also ensures storing energy relating data at a low cost (Amin, 2015; Clastres, 2011; Moslehi \& Kumar, 2010).

\subsection{The Positive Effects of the Implementation of ICT in Maintaining Efficient and Effective Energy Supply}


The implementation of ICT technology also supports in maintaining efficient along with effective energy supply, which, in turn, contributes to the betterment of the people. It also involves effectively lowering and controlling energy consumption. The use of ICT technology leads to efficient saving of energy and user optimum convenience in energy usage. It leads to the development of infrastructure that, in, turn contributes to the effective energy supply. Cloud technology is useful in the development of the green control station, which involves the presence of renewable energy. It involves the supply of energy for a long-term, which is unlike in case of non-renewable energy sources that are limitedly available. In addition, micro electric components when involved with ICT support the effective heat management. Contextually, the heat can be effectively controlled as per the requirement through the use of ICT, which particularly involves cloud and internet technology. Additionally, ICT technology further includes sleep mode or auto start process controlled by internet technology. Thus, it ensures effective supply of energy. It also reduces the wastage of energy, which, in turn, reflects the improved efficiency of the sector. The ICT system supports ineffective tracking as well as calculating the energy supply process, which further assists in attaining real time feedback (Laudon, K. C. \& Laudon, J. P., 2016; Ehsan \& Hamdaoui, 2012; Watson, Boudreau, \& Chen, 2010).

\subsection{Ways to Address the Energy Problems in the Third World}

\section{Countries}

The third world countries have been facing major issues of an energy crisis due to a lack of effective infrastructure along with insufficient fund. However, this issue can be resolved by the application of ICT. The use of ICT in the third world countries would facilitate in gaining along with assessing information, which, in turn, contribute to conducting innovation in the energy sector. This, in turn, leads to an increased generation of energy as well as its efficient distribution throughout the nation. The wastage of energy has been a common issue in the underdeveloped, which can be addressed by the implementation of ICT. In addition, ICT involves tracking of the energy performance and identifying, wherein there is wastage of energy. The immediate addressing of the issue leads to the cost saving of the energy sector. This 
is extremely crucial from the perspective of a third world nation. The use of ICT in the energy sector in the third world nations leads to the improvement of the infrastructure, which has been the major issue prevailing in these countries. The infrastructural development contributes to the increased energy. In the third world nations, ICT can also be used to aware people regarding the importance of saving energy and the ways it can be conducted by consumers. The use of ICT in the third world nations would result in the improvement of environment and the health of people therein, as it promotes reduced carbon emission (Giddens, 2018; Action, 2013; Brew-Hammond, 2010).

\section{Conclusions \& Recommendations}

Based on the overall discussion, it is apparent that ICT significantly contribute to energy security as well as efficiency assurance. It supports in overcoming the technical issues in energy management along with, maintaining efficient, and effective energy supply and reduction of the cost. It mainly involves the use of cloud and internet technology, radio frequency, GPRS, various software, and hardware along with the computerized processing of several related information. Thus, it largely helps the underdeveloped countries in mitigating the issue of the energy crisis. The improved communication through the integration of ICT assists in immediately addressing the supply chain issues of the energy sector. It also assists in reducing wastages, thereby contributing towards reducing the involved costs along with the greater maintenance of higher efficiency and energy security. ICT also supports in conducting of innovation that supports in the identification of new efficient energy at reduced cost. Moreover, ICT assists in improving the infrastructure in the energy supply process. This, in turn, ensures that energy is available at all places in the region. The integration of ICT also helps in promoting the use of renewable energy throughout the world. It ensures the protection of the environment along with the maintenance of people's health, as it involves reduced carbon emission.

Based on the findings of this study, it is recommended that all the nations throughout the world including the underdeveloped countries must integrate ICT. 
This, in turn, would support in overcoming the energy crisis. It is particularly recommended to the energy sector that it should extensively use internet and cloud technology, GPRS, radio frequency technology along with the use of varied software and hardware for effective management of energy security and efficiency assurance. It will largely contribute to the further development of the global economy, society, and environment. Besides, this study is recommended to the future researchers in further researching on how ICT can be used for energy security along with efficiency assurance. It is recommended to the future researchers that they can use this study as a secondary source, which involves the presence of recent as well as relevant information.

\section{References}

Action, P. (2013). Poor people's energy outlook 2013: Energy for community services. New York: Practical Action Publishing.

Adejumobi, I. A., Oyagbinrin, S. G., Akinboro, F. G., \& Olajide, M. B. (2011). Hybrid solar and wind power: An essential for information communication technology infrastructure and people in rural communities. IJRRAS, 9(1), 130-138.

Amin, M. (2015). Smart grid. Public Utilities Fortnightly, 24-32.

Armaroli, N. \& Balzani, V. (2007). The future of energy supply: challenges and opportunities. Angewandte Chemie International Edition, 46(2), 52-66.

Beggs, C. (2010). Energy: Management, supply and conservation. London: Routledge.

Bilbao-Osorio, B., Dutta, S., \& Lanvin, B. (2013). The global information technology report 2013. World Economic Forum, 1-383.

Bokor, L. (2013). The energy resources and their importance in the local environment. Locality, 1(1), 14-19. 
Brew-Hammond, A. (2010). Energy access in Africa: Challenges ahead. Energy Policy, 38(5), 2291-2301.

Buabeng-Andoh, C. (2012). Factors influencing teachers' adoption and integration of information and communication technology into teaching: A Review of the literature. International Journal of Education and Development using Information and Communication Technology, 8(1), 136-155.

Chapelle, C. A. (2003). English language learning and technology: Lectures on applied linguistics in the age of information and communication technology. New York: John Benjamins Publishing.

Clastres, C. (2011). Smart grids: Another step towards competition, energy security and climate change objectives. Energy Policy, 39(9), 5399-5408.

Coyle, E. D. \& Simmons, R. A. (2014). Understanding the global energy crisis. Purdue University Press, 1-282.

Ehsan, S. \& Hamdaoui, B. (2012). A survey on energy-efficient routing techniques with QoS assurances for wireless multimedia sensor networks. IEEE Communications Surveys \& Tutorials, 14(2), 265-278.

Erdinc, O., \& Uzunoglu, M. (2010). Recent trends in PEM fuel cell-powered hybrid systems: Investigation of application areas, design architectures and energy management approaches. Renewable and Sustainable Energy Reviews, 14(9), 28742884.

Festus, M. O. \& Ogoegbunam, O. B. (2015). Energy crisis and its effects on national development: The need for environmental education in Nigeria. British Journal of Education, 3(1), 21-37.

Flick, U. (2018). An introduction to qualitative research. New York: Sage Publications Limited. 
Gharavi, H., \& Ghafurian, R. (2011). Smart grid: The electric energy system of the future. IEEE, 99(6), 917-921.

Giddens, A. (2018). Globalization. London: Routledge.

Giorgi, A. (2009). The descriptive phenomenological method in psychology: A modified Husserlian approach. New York: Duquesne University Press.

Gratton, C. \& Jones, I. (2010). Research methods for sports studies. London: Routledge.

Gubbi, J., Buyya, R., Marusic, S., \& Palaniswami, M. (2013). Internet of things (IoT): A vision, architectural elements, and future directions. Future generation computer systems, 29(7), 1645-1660.

Hannan, M. A., Azidin, F. A., \& Mohamed, A. (2012). Multi-sources model and control algorithm of an energy management system for light electric vehicles. Energy Conversion and Management, 62, 123-130.

Jacobson, M. Z. \& Delucchi, M. A. (2011). Providing all global energy with wind, water, and solar power, Part I: Technologies, energy resources, quantities and areas of infrastructure, and materials. Energy policy, 39(3), 1154-1169.

Kabalci, E. (2013). Design and analysis of a hybrid renewable energy plant with solar and wind power. Energy Conversion and Management, 72, 51-59.

Kalogirou, S. A. (2013). Solar energy engineering: Processes and systems. New York: Academic Press.

Kilian, L. (2008). The economic effects of energy price shocks. Journal of Economic Literature, 46(4), 871-909. 
Kuravi, S., Trahan, J., Goswami, D. Y., Rahman, M. M., \& Stefanakos, E. K. (2013). Thermal energy storage technologies and systems for concentrating solar power plants. Progress in Energy and Combustion Science, 39(4), 285-319.

Laudon, K. C. \& Laudon, J. P. (2016). Management information system. New Delhi: Pearson Education India.

Lee, K. \& Ni, S. (2002). On the dynamic effects of oil price shocks: A study using industry level data. Journal of Monetary Economics, 49(4), 823-852.

Lillis, T. \& Curry, M. J. (2013). Academic writing in a global context: The politics and practices of publishing in English. London: Routledge.

Luić, L. \& Glumac, D. (2009). The role of ICT technology in the knowledge society. IEEE, 310-313.

Manieniyan, V., Thambidurai, M., \& Selvakumar, R. (2009). Study on energy crisis and the future of fossil fuels. SHEE, 10(2), 2234-3689.

Maxwell, J. A. (2012). Qualitative research design: An interactive approach. New York: Sage publications.

Mbunwe, M. J. (2014). Analysis of energy crisis and how it affects production sector and economic growth of Nigeria. WCECS, 1, 22-24.

McDaniel, C. \& Gates, R. (2013). Marketing research. Singapore: Wiley.

McKillop, A. (2008). The final energy crisis. London: Pluto Press.

Mechtenberg, A. R. (2009). Understanding the importance of an energy crisis. Abigail Reid Mechtenberg, 1-43.

Mekhilef, S., Saidur, R., \& Safari, A. (2011). A review on solar energy use in industries. Renewable and sustainable energy reviews, 15(4), 1777-1790. 
Mensah-Bonsu, C. \& Oren, S. (2002). California electricity market crisis: Causes, remedies, and prevention. IEEE Power Engineering Review, 22(8), 4-11.

Miller, T., Birch, M., Mauthner, M., \& Jessop, J. (2012). Ethics in qualitative research. New York: Sage.

Moslehi, K. \& Kumar, R. (2010). A reliability perspective of the smart grid. IEEE Transactions on Smart Grid, 1(1), 57-64.

Ndibalema, P. (2014). Teachers' attitudes towards the use of information communication technology (ICT) as a pedagogical tool in secondary schools in Tanzania: The case of Kondoa District. International Journal of Education and Research, 2(2), 1-16.

Pathak, S. (2014). Energy crisis: A review. Journal of Engineering Research and Applications, 4(3), 845-851.

Qasim, M. \& Kotani, K. (2013). Causes of energy shortage in Pakistan: An empirical evidence. Economics \& Management Series, 1-25.

Quinlan, C., Babin, B., Carr, J., \& Griffin, M. (2018). Business research methods. Boston: South Western Cengage.

Rienties, B., Kaper, W., Struyven, K., Tempelaar, D., Van Gastel, L., Vrancken, S., \& Virgailaitè-Mečkauskaite, E. (2012). A review of the role of Information communication technology and course design in transitional education practices. Interactive Learning Environments, 20(6), 563-581.

Ritchie, J., Lewis, J., Nicholls, C. M., \& Ormston, R. (2013). Qualitative research practice: A guide for social science students and researchers. New York: Sage.

Ritchie, J., Lewis, J., Nicholls, C. M., \& Ormston, R. (2013). Qualitative research practice: A guide for social science students and researchers. New York: Sage. 
Sharma, A., Gandhar, K., Sharma, S., \& Seema, S. (2011). Role of ICT in the process of teaching and learning. Journal of Education and Practice, 2(5), 1-6.

Silverman, D. (2016). Qualitative research. New York: Sage.

Singh, N. (2016). Information technology and its role in India's economic development: A review. Springer, 283-312.

Smith, J. A. (2015). Qualitative psychology: A practical guide to research methods. New York: Sage.

Stošić-Mihajlović, L. \& Trajković, S. (2018). The importance of energy for the economy, sustainable development and environmental protection: An economic aspect. Journal of Process Management. New Technologies, 6(1), 20-26.

Vaishnavi, V. K. \& Kuechler, W. (2015). Design science research methods and patterns: innovating information and communication technology. New York: CRC Press.

Volyand, F., Woodman, P., Hook, C., Reece, M., \& Fagan, J. M. (2010). The importance of energy conservation: Raising awareness in today's youth. EPA Energy Conservation, 1-5.

Wang, Q., \& Woo, H. L. (2007). Systematic planning for ICT integration in topic learning. Educational Technology \& Society, 10(1), 148-156.

Watson, R. T., Boudreau, M. C., \& Chen, A. J. (2010). Information systems and environmentally sustainable development: Energy informatics and new directions for the IS community. MIS quarterly, 23-38.

Whitford, A. B. (2016). Estimation of several political action effects of energy prices. Energy and Policy Research, 3(1), 13-18. 
Williams, J. L., \& Alhajji, A. F. (2003). The coming energy crisis. Oil and Gas Journal, 101(5), 1-13.

Yan, Y., Qian, Y., Sharif, H., \& Tipper, D. (2013). A survey on smart grid communication infrastructures: Motivations, requirements and challenges. IEEE communications surveys \& tutorials, 15(1), 5-20. 